\title{
Imported Tertian Malaria Resistant to Primaquine
}

\author{
Dong Jib Na,M.D., Jong Dae Han,M.D., Dong Youb Cha,M.D. \\ In Kwan Song,M.D., Hwan Won Choi,M.D.,Eun A Chung,M.D. \\ Chan wook Park M.D.,Jong Sung Choi*,M.D. \\ Department of Internal Medicine and Clinical Pathology*, \\ $S$ un General Hospital, Dae Jeon, Korea

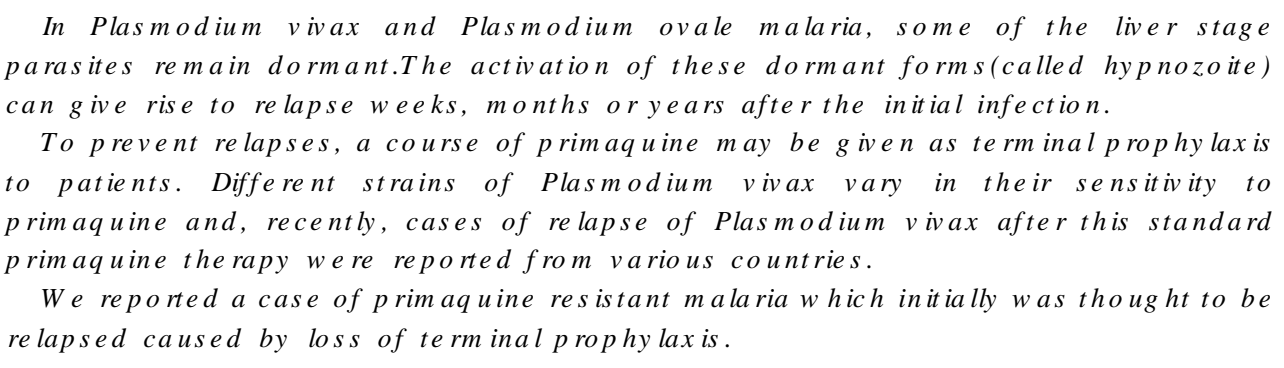

Ke y Wo rds: Plasmodium vivax, primaquine, resistant

\section{INTRODUCT ION}

It has been claimed that tertian malaria had been completely eradicated in the latter part of 1970 in Korea ${ }^{1)}$. But since 1993, this tertian malaria has reemerged to infect soldiers and civilians living near the armistice line ${ }^{2)}$, resulting in 1,724 cases in $1997^{3)}$. Also, imported malaria from an overseas trip has become a medical problem to the extent of calling attention. Reports have appeared calling attention to what has been termed primaquine resistance in Plasmodium vivax in Korea ${ }^{4), 5)}$.

We present a case of primaquine resistant tertian malaria which was thought to be relapsed because of loss of radical cure at initial treatment.

\section{CASE REPORT}

A 50-year-old man presented on November, 1997 with high fever, chills and splenomegaly. Three weeks before admission, he had traveled to Ethiopia where he had remained for 10 days without prophylactic chemotherapy

Address reprint requests to : Dong Jip Na, M.D., Department of intermal Medicine, Sun General Hospital, 10-7 Mok Dong, Jung Gu, Dae Jeon, 301-070, Korea against malaria.

The temperature was $39^{\circ} \mathrm{C}$, the pulse was $100 / \mathrm{min}$ and the respiration rates were $22 / \mathrm{min}$. The blood pressure was $110 / 80 \mathrm{mmHg}$.

A physical examination was normal, except for a nontender, firm splenomegaly exceeding $5 \mathrm{~cm}$ below the costal margin. An ultrasonogram of the abdomen revealed enlargement of the spleen and slight hepatomegaly. Laboratory examinations showed hemoglobin $16.1 \mathrm{gm} / \mathrm{dl}$, white blood cell count $7,510 / \mathrm{mm}^{3}$, platelet count $49,100 / \mathrm{mm}^{3}$, alkaline phos phatase $248 \mathrm{IU} / \mathrm{L}$, alanine aminotransferase $165 \mathrm{IU} / \mathrm{L}$, aspartate aminotransferase $89 \mathrm{IU} / \mathrm{L}$. At that time, microscopic examination of a blood smear was said to show malaria (P.vivax) and a diagnosis of malaria was made. After treatment with chloroquine $(750 \mathrm{mg}$ as a loading dose and then $350 \mathrm{mg}$ each $6,24,48$ hours later), he felt well but subsequently did not receive primaquine because of the physician's mistake.

After about three months, he became ill with fever and chills. Laboratory examinations showed hemoglobin 16.5 $\mathrm{gm} / \mathrm{dl}$, white blood cell count $4,150 / \mathrm{mm}^{3}$, platelet count $26,300 / \mathrm{mm}^{3}$. Microscopic examination of a stained blood s mear for malarial organism $(38,180 / \mu l)$ was positive. The patient was given a conventional three-day course of chloroquine with relapsed malaria. On the following day, 
he became afebrile and reevaluation of blood smears showed decrease in the number of parasite counts $3,480 /$ $\mu \ell)$. He subsequently was given primaquine $(15 \mathrm{mg}$ base daily for 14 days) with improvement. The test of G-6PDH (glucose-6-phosphate dehydrogenase) deficiency was negative $(11.7 \mathrm{U} / \mathrm{g})$.

About three months after the first relapse, however, he revisited the hospital with fever, headache and chills. Physical examination showed no change, except that the spleen was felt $4 \mathrm{~cm}$ below the costal margin. Peripheral blood examination showed variable forms of P.vivax (Fig. 1) with reduction in platelet count $\left(97,000 / \mathrm{mm}^{3}\right)$. He was given a diagnosis of primaquine resistant malaria. The patient was treated with chloroquine in the same dose as the in first attack. On the next day, he became afebrile and smear for malarial organisms had become negative. He subsequently received primaquine $(22.5 \mathrm{mg}$ daily for 21 days) without side effects from the drug. One month later, he was well and the spleen was no longer palpable. Symptoms have not relapsed during 5 months of observation.

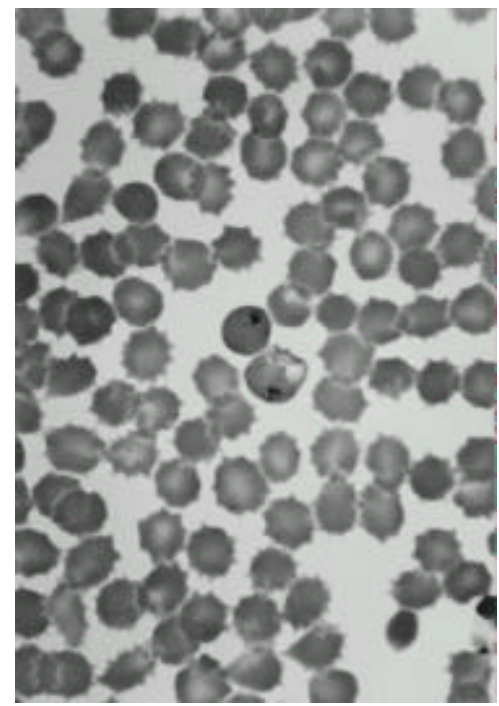

zones, increasing numbers of travelers from temperate areas each year vis tropical countries where the disease remains a major cause of morbidity and death.

Relapse occurs with P.vivax infections because delayed developmental forms of the parasite, called hypnozotes, are present in the liver. Hypnozotes can mature months to years later to cause clinical disease. After maturing and multiplying in the liver, the parasites enter a red blood cell for further development. Clinical disease is produced when parasites are released from red blood cells. A radical cure is achieved for P.vivax infections by the use of both blood-stage antimalarial drugs and primaquine, which is the only available drug that can destroy hypnozoites. To provide radical cure of P.vivax malaria, treatment must be prescribed to eliminate the liver stage of the parasites, otherwise intermittent relapses with clinical symptoms will continue.

Usually, after acute phase therapy with chloroquine, patients with P.vivax are treated with the standard course of primaquine, i.e. $15 \mathrm{mg}$ base/day for 14 days, as curative therapy. Primaquine- resistant strains have been reported from Papua New Guinea, South- East Asia and

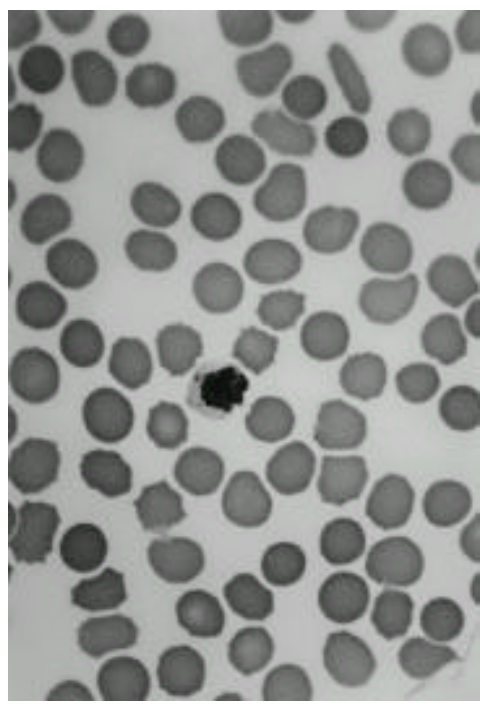

Fig. 1. Ring form of Plasmodium vivax (left) and a schizont of P.vivax (right) (Wright- Giemsa stain, x 1000).

\section{DIS C US S ION}

Malaria is the world's most important parasitic infection. Although it has been eradicated from temperate
Central and South America. Cases of primaquine treatment failure have also been reported in patients who visited Kenya, Sudan and Ethiopia ${ }^{6}$. The interval between primary infection and relapse varies with differing strains 
of P.vivax-Chesson strain from Papua New Guinea relapsing rapidly, at intervals of 28 days; strains from Southern China may relapse on an approximately annual basis. Such strains appear to show intrinsic differences in sensitivity to 8-aminoquinolines, the agents most commonly used to eradicate the liver stage. Studies carried out in the Western Pacific Region soon after World Warll, and predominantly involving the Chesson strains, indicated that a regimen of primaquine base 15 $\mathrm{mg} /$ day for 14 days led to failure in over $30 \%$ of cases ${ }^{7}$. I would appear that this investigation regimen was selected solely on the basis of limiting potential toxicity. Common practice over subsequent decades within this region has been to use a regimen of primaquine base 22.5-30 mg/day for 14 days to ensure a high chance of parasite eradication ${ }^{8)}$. In contrast, however, studies during the Vietnam War determined that strains from South- East As ia were more primaquine-sensitive and were almost entirely eradicated with primaquine base $15 \mathrm{mg} /$ day for 14 days ${ }^{9)}$.

Strains from South- East Asia and Central and South America have also been reported to relapse after standard regimens of primaquine ${ }^{10)-12)}$. Most authorities agree that it is reasonable to treat patients who acquire their infections from these areas with a higher dose regime ${ }^{13)}$. To reduce side effects, a regimen of $15 \mathrm{mg}$ daily of primaquine base for 28 days has been used instead of $30 \mathrm{mg}$ base daily for 14 days, under the assumption that it is the total, cumulative dose of primaquine that is important in eliminating hypnozoites. Unfortunately, there are no data to support the longer duration regimen. Human and animal studies have only used total doses scheduled over a shorter time interval (60 mg base daily for 7 days versus $30 \mathrm{mg}$ base daily for 14 days) in showing equivalent cure rates ${ }^{14)}$-15).

It is curious that primaquine resistance emanates from areas where higher doses of primaquine have been used for longer periods. Whether this increased anti-malarial load is a risk factor for primaquine tolerance is uncertain. Animal and human studies of sub-therapeutic doses of primaquine in P.vivax infections resulted only in resistance in the erythrocytic stages of the life cycle ${ }^{16)}$. While it has been suggested that the apparent increasing resistance to primaquine in P.vivax actually reflects unrecognized chloroquine-resistance in this parasite, at present, recurrence of vivax parastemia after primaquine therapy and $>28$ days from initial infection more often represents primaquine rather than chloroquine failure.
Cause of the first relapse in our patient is thought to be inadequate regimen rather than chloroquine resistance: primaquine was not prescribed at initial infection. Second attack was due to primaquine resistance, since the peripheral blood smear of our patient was normal up to three days after the treatment (chloroquine) and relapse took place after three months. Moreover, he had traveled to Ethiopia where primaquine treatment failure has been reported $^{6}$.

Primaquine may cause nausea and abdominal pain, particularly if taken on an empty stomach and, more important, oxidant hemolys is with methemglobinemia, anemia and, sometimes, hemoglobinuria. Patients with a deficiency of glucose-6-phosphate dehydrogenase are particularly vulnerable to oxidant hemolysis, and primaquine is contraindicated in patients with severe form of the deficiency. In places where mild variants of glucose-6-phosphate dehydrogenase deficiency are common, primaquine $(0.8 \mathrm{mg}$ of base per kilogram; adult dose, $45 \mathrm{mg}$ ) should be given once a week for six weeks for a radical cure ${ }^{17)}$.

I is imperative to establish the most appropriate regimen with primaquine for the curative treatment of relapsed vivax malaria after the completion of chloroquine- primaquine therapy.

\section{REFERENCES}

1. Soh CT, Lee KT, Im KL, Min DY, Ahn MH, Kim JJ, Yong TS. Current status of malaria in Korea.Yonsei Rep Trop Med 1985; 16:11- 18.

2. Yim HW, Suh GY, Ahn YS, Oh SY, Kim DL, Lim CS. Epidemiologic and clinical anabsis of 87 indigenous malaria in Korean soldiers in 1995.Korean J Infect Dis 1996; 282 19-224.

3. Anonymous national communicable disease report by month and area, 1997. 2 CDMR 1998; 9023.

4. Kim JS, Park KS, Lee JM, Choi JH, Lee IS, Kim MY, Kim YR, Kang MW. A case of primaquine resistant tertian malaria. Korean J infect Dis 1997; 6:503-507

5. Yi KJ, Chung MH, Kim HS, Kim CS, Pai SH A relapsed case of imported tertian malaria after a standard course of hydroxychloroquine and primaquine therapy.Korean $J$ Parasitol 1998; 36:143- 146.

6. Jelinek T, Nothdurtt HD, Von Sonnenburg F, Loscher T. Long-term efficacy of primaquine in the treatment of vivax malaria in nonimmune travelers. Am J Trop Med Hyg 1995; $52: 322-324$.

7. Cooper WC, Myatt AV, Hernandez T, Jeffery GM, Coatney GR. Studies in human malariaXXXI. Comparison of primaquine, isopentaquine, $S N-3883$ and pamaquine as 
curative agents against Chesson strain vivax malariaAm J Trop Med Hyg 1953; 2.949-957.

8. Black RH. Malaria in refugees from Indo-China as seen in Australia in 1980. Med J Aust 1980; 2:324-325.

9. Fisher GU, Gordon MP, Lobel HO, Runcik K. Malaria in soldiers retuming from Vietnam.Epidemiologic, therapeutic and clinical studies. Am J Trop Med Hyg 1970; 19:27-39.

10. Bunnag D, Karbwang J, Thanavibul A, Chittamas S, Ratanapongse $\mathrm{Y}$, Chalermrut $\mathrm{K}$, Bangchang $\mathrm{KN}$, Harinasuta T. High dose of primaquine in primaquine resistant vivax malaria.Trans $R$ Soc Trop Med Hyg 1994; 882 18-219.

11. Oldfield III ED, Rodier GR, Gray CG. The endemic infectious disease of Somalia.Clin Infect Dis 1993; 16: S 132 - $S 157$.

12. Wallace MR, Sharp TW, Smoak B, Iriye C Rozmajzl P, Thornton SA, Batchelor R, Magill AJ, Lobel HO, Longer CF, Burans JP. Malaria among US troops in Somalia. Am
J Med 1996; 100:49-94.

13. Hoffman SL. Diagnosis,treatment, and prevention of malaria. Med Clin North Am 1992; 76:1327- 1355.

14. Clyde DF, McCarthy VC. Radical cure of Chesson strain vivax malaria in man by 7,not 14,days of treatment with primaquine.Am J Trop Med Hyg 1977; 26:562-563.

15. Schmidt LH, Fradkin R, Vaughan D, Rasco J. Radical cure of infections with Plasmodium cynomolgi: a function of total 8-aminoquinoline dose. Am J Trop Med Hyg 1977; 26:1116- 1128.

16. Arnold J, Alving AS, Clayman CB.Induced primaquine resistance in vivax malaria. Trans $R$ Soc Trop Med Hyg 1961; 55:345-350.

17. Bruce-Chwatt LJ, Black RH, Canfield CJ, Clyde DF, Peter W, Wernsdorfer WH. Chem otherapy of malaria. 2nd ed. World Health Organization monograph series no.27. Geneva: World Health Organżation, 1981. 